\title{
Cantos que aprendemos nos sonhos: os grupos de canto/corais Ava-guarani e a transmissão de saberes através da experiência onírica na aldeia Ocoy/ Paraná.
}

Denize Refatti

Resumo: Este artigo tem como mote principal descrever as relações existentes entre os sonhos e os Ava-guarani, refletindo principalmente sobre como os sonhos estão presentes na transmissão de saberes dos grupos de canto da aldeia indígena Ocoy, em São Miguel do Iguaçu - Paraná. Considero que os sonhos são experiências coletivas que envolvem um conjunto de atividades, e possibilitam o acesso a um plano cosmológico que orienta a vida cotidiana. O artigo aponta para os modos como os cantos dos corais se afinam com a experiência onírica no que se refere aos conteúdos, às iniciações, à execução de instrumentos, entre outras dinâmicas que fazem parte das atividades dos grupos de canto.

Palavras-chave: Ava-guarani. Sonhos. Conhecimento. Cantos.

\section{Songs we learn in dreams: the singing groups / corals Ava-guarani and the transmission of knowledge through the oniric experience in the aldeia Ocoy/ Paraná.}

\begin{abstract}
This article has as its main theme, to describe the relationships between dreams and the Ava-Guarani of the indigenous village Ocoy, in São Miguel do Iguaçu - Paraná. I consider that dreams are collective experiences involving a set of activities, and allow access to a cosmological plan that guides the daily life. The article points to the ways in which the choral chants are in tune with the dream experience, with regard to the contents, the initiations, the execution of instruments and other dynamics that are part of the activities of the singing groups.
\end{abstract}

Keywords: Ava-Guarani. Dreams. Knowledge. Singing.

\footnotetext{
Mestrapeloprogramadepós-graduaçãoem AntropologiaSocialdaUniversidadeFederaldeSantaCatarina(UFSC), onde atualmente cursa doutorado. Graduada em Ciências Sociais pela Universidade Estadual do Oeste do Paraná. E-mail: denizerefatti@gmail.com
} 


\section{Introdução}

Partindo das dinâmicas relacionadas aos grupos de canto/corais, este artigo se debruça em pensar a experiência onírica como um processo legítimo de conhecimento entre os Ava-guarani. Com base no princípio de que os sonhos são compreendidos, vivenciados e interpretados de diferentes maneiras de acordo com os contextos socioculturais, busco demonstrar que, para os Ava-guarani do Ocoy, os sonhos se destacam como um dos diferentes modos de transmissão de ideias, tradições e de conhecimentos. Esta reflexão está fundamentada em minha pesquisa de mestrado com os Ava-guarani do Tekoa Ocoy em São Miguel do Iguaçu, município do oeste paranaense, localizado próximo à tríplice fronteira entre Brasil, Paraguai e Argentina.

Embora os sonhos não ocupem um lugar de destaque para um grande número de pessoas na sociedade ocidental, sendo compartilhados principalmente nas sessões de psicanálise ou em esporádicas narrativas e interpretações, este comportamento não deve ser entendido como a única forma de nos relacionarmos com nossos sonhos, uma vez que cada cultura atribui valor e interpreta seus sonhos a partir de suas próprias perspectivas. Desta maneira, o impacto dos sonhos no cotidiano de cada grupo também adquire características próprias, o que nos possibilita entender o universo onírico como cerne principal na cultura de alguns grupos.

Estudos antropológicos mais recentes avançam nesse debate uma vez que buscam a compreensão das teorias nativas por elas mesmas, abdicando-se de ressignificações e interpretações que nem sempre são condizentes com a realidade vivenciada pelo grupo estudado. Neste sentido, os estudos do fenômeno onírico deixam de se preocupar apenas com a compreensão em torno dos conteúdos dos sonhos, passando a abarcar também o contexto em que o sonho é produzido, em que é compartilhado e interpretado.

Pesquisas como a de Tassinari (2008, p.238), que apontam para os processos nativos de ensino aprendizagem, entendem que para populações ameríndias os sonhos também são fontes legítimas de saber, uma vez que os conhecimentos também podem ser transmitidos através de transes, ingestão de bebidas sagradas e outros rituais nos quais "há o reconhecimento de que certos saberes dependem de estados alterados de consciência para serem compreendidos, transmitidos ou incorporados". A relevância dos processos nativos de transmissão de saberes reforçam a importância dos sonhos como um campo pouco explorado, no entanto, fundamental para compreender processos indígenas de ensinar e aprender. De acordo com Antonella Tassinari, a aprendizagem por meio dos sonhos merece destaque, porque há vários exemplos etnográficos referentes a situações em que os neófitos são treinados para sonhar, revelando o "sonho como uma fonte legítima e importante de saber" (2008, p. 238).

As crianças ouvem e aprendem sobre estas técnicas desde cedo e igualmente são estimuladas a contar seus sonhos e a escutar com atenção quando alguém está fazendo a narrativa de um sonho. Parecem não se importar com as conversas dos adultos, enquanto brincam descompromissadamente pelos arredores da casa, mas é dessa forma, escutando uma ou outra conversa, que começam a entender o quanto é importante escutar essas narrativas e aos poucos se arriscam contando os seus próprios sonhos, elas acordam e dizem que aprenderam, que brincaram, que viram coisas ou se encontraram com pessoas enquanto sonhavam. 
A rotina dos Ava-guarani começa cedo. Antes dos primeiros raios de sol, entre cinco e seis horas da manhã, eles levantam e começam a se preparar para o dia que os espera. Acendem o fogo de chão, preparam o reviro ${ }^{2}$ e bebem o chimarrão, intercalando longos minutos de silêncio com conversas descontraídas. Esse momento é geralmente o escolhido para se compartilhar os sonhos que tiveram à noite e, portanto, o momento que se tornou o cerne de minha pesquisa, porque era nessa hora que eu procurava me sentar com eles para falar sobre o universo dos sonhos. Foi despertando antes das seis horas da manhã que aprendi com os guarani a acordar o dia e não a ser acordada por ele, como costumam dizer os mais velhos, e foi assim também que compreendi grande parte das informações que compartilho a seguir.

\section{Compreendendo os sonhos como processos legítimos de conhecimento}

A experiência onírica perpassa diferentes instâncias da vida no Ocoy, sendo um instrumento importante da religiosidade guarani e de grande domínio de especialistas como o chamo' ${ }^{3}$ ou a chara'i, exímios conhecedores do universo dos sonhos e que, portanto, são frequentemente procurados para ajudar na interpretação destes, o que não exclui a possibilidade de pessoas consideradas comuns também se debruçarem sobre a experiência onírica de modo a teorizar os sonhos, avisos, conhecer remédios, cantos e rezas, bem como se comunicar com Nhanderu ${ }^{4}$ e com os mortos através do sonho, podendo ainda ser capaz de interpretar a maioria deles.

Para os Ava-guarani, as imagens vistas durante o sono são sagradas e, por isso, permanecem vivas na memória durante vários dias, semanas ou até mesmo anos; portanto, enquanto forem lembradas podem ser relacionadas a uma série de acontecimentos. Dessa maneira, se alguém sofre um acidente ou chega a falecer, por exemplo, é possível que algumas pessoas relacionem o fato recém-ocorrido a sonhos que tiveram na semana anterior ou até no mês anterior. Os sonhos estão intimamente ligados ao dia a dia guarani e compreendem uma experiência coletiva, uma vez que devem ser compartilhados com outras pessoas, envolvendo membros da família, outros moradores da comunidade e até os parentes que moram em aldeias distantes.

Para os Ava-guarani, o sonho nunca pode ser entendido como simples atividade fisiológica do corpo humano, porque organizam seus dias e suas vidas a partir de cada imagem que compõe uma experiência onírica; por isso, contar um sonho constitui-se numa minuciosa tarefa da qual não se pode esquecer nenhum detalhe, motivo pelo qual algumas narrativas podem durar mais do que uma hora. São esses pequenos detalhes que fundamentam os significados dos sonhos; por isso, é preciso prestar muita atenção quando um guarani conta seu sonho se queremos ajudar a interpretá-los. Por exemplo, um sonho no qual aparece a figura de um peixe dourado é interpretado como uma oportunidade para se adquirir dinheiro, enquanto o mesmo sonho protagonizado por um peixe prateado e de couro pode ser interpretado como um mau agouro.

2 O reviro é uma das principais comidas consumidas no Ocoy, geralmente feita pela mulher mais velha da casa. No entanto, durante meu campo observei muitos homens e crianças preparando este prato, que é servido pela manhã e no final do dia, sempre acompanhado de café ou de chimarrão. Seu preparo necessita apenas de: farinha, água, sal e um pouco de óleo ou banha de porco.

3 Os Chamo'is (masculino) e chara'is (feminino) são os especialistas do xamanismo guarani. No Ocoy, usa-se pouco a palavra pajé, porque os guarani a relacionam com atividades de bruxaria, "feitiços de maldade" e outras atividades que não condizem com a verdadeira missão xamânica de proferir belas palavras e curar doenças.

4 O nosso pai - O nosso Deus, na religiosidade guarani. 
No Ocoy, muitas pessoas me disseram que de nada adianta um sonho se ele não for compartilhado com familiares e/ou amigos. O compartilhamento dos sonhos é importante, porque as imagens oníricas são mensagens que devem ser passadas adiante, inclusive porque muitas delas podem evitar acontecimentos ruins, serem decisivas na tomada de uma decisão ou direcionar o sonhador para os melhores caminhos. É por isso também que alguns sonhos são rememorados, em vários momentos ao longo do dia, pela pessoa que teve o sonho ou pelas pessoas que ouviram esse sonho ser compartilhado.

Enquanto um Ava-guarani dorme, seu corpo permanece em repouso, diferente do que acontece com sua alma, que pode percorrer caminhos que lhe permitem estabelecer conexões com outros mundos, com seres sagrados e com os mortos. Desses caminhos, a alma traz mensagens, avisos, premonições e ensinamentos, podendo também percorrer caminhos nunca antes visitados, o que permite ao sonhador um mergulho no desconhecido, no qual pode, inclusive, conhecer paisagens nunca antes vistas e aumentar o conhecimento do sobrenatural. Deste modo, os sonhos são um meio importante para o desenvolvimento da consciência e da imaginação, já que são o "principal canal de conhecimento entre o espírito do sonhador e dos espaços distantes ou invisíveis" (OTERO, 2010, p.36).

Montardo, apresentando o trabalho de Bartolomé e Barabas (1991), comenta que o sonho xamanístico pode ser entendido como uma ponte entre a cosmovisão mítica e a sociedade, ou seja, ele é um canal de comunicação entre realidades alternativas, e ao passo que torna o mito continuamente presente, é capaz de reforçar a ordem social (2002, p. 48). Dessa forma, nas palavras de Montardo (2002), "os sonhos indicam possibilidades" que são interpretadas no decorrer do dia e são determinantes para a rotina dos guarani. Em sua pesquisa sobre a música dos rituais xamanísticos guarani, a autora explica que o jeroky (ritual coletivo) é fundamental para a sobrevivência do grupo, de modo que o canto e a dança constituem aspectos centrais da sua cultura, tendo o sonho como um elemento importante dessa prática (2002, p.54).

A ideia de caminho proposta por Montardo é muito importante para percebermos o papel dos sonhos no xamanismo guarani, uma vez que grande parte das atividades dos xamãs acontecem nos sonhos. A autora destaca que é no sonho que se "vai lá", ou, em outras palavras, os sonhos são um dos caminhos percorridos pelos xamãs para se ter acesso ao sagrado.

De maneira muito semelhante, Langdon refere-se ao sonho Siona como viagem, na qual o "sonhador se desloca até as áreas invisíveis do universo" (1999, p.39). Viagem ou caminho, essas duas concepções compreendem a relação dos sonhos com o misterioso mundo do invisível e com o impacto que produzem no cotidiano indígena. As inspirações oníricas, capazes de pôr em movimento famílias inteiras, também contribuem para a experiência do existir guarani, uma vez que os sonhos são capazes de acionar e produzir modos de perceber e interpretar o mundo como ferramentas que permitem que a alma (nhe'e) percorra caminhos e estabeleça comunicação com as divindades.

Esses caminhos não são percorridos apenas para os levar de um lugar a outro, uma vez que fazem parte de muitos outros elementos da cosmologia guarani, como o jeroky (ritual, música e dança) que revela as concepções guarani sobre as transformações do corpo: pesado em leve, do agressivo em alegre. Assim, à medida que as canções vão sendo executadas e dançadas, os guarani percorrem um caminho ao encontro das divindades (MONTARDO, 2002). 
Montardo (2002) explica que este caminho também é percorrido durante o processo de composição das músicas e, quando se dá a iniciação ao xamanismo, porque é no sonho que se "vai lá" onde estão os elementos da cultura guarani, como a comida, objetos e adornos, tudo isso se abre para as pessoas durante o sonho. Para Dona Odúlia, interlocutora na pesquisa de Montardo, os sonhos estão presentes em todos os momentos que compõem o jeroky, desde a inspiração, a confecção do mbaraka, em que Pa'i Kuara (dono do sol) escolhe as sementes que devem ser utilizadas até a sua execução, o que permite a autora afirmar que os xamãs cantam para expressar o ponto de vista dos deuses.

Aty Mirí e Tupã Vy'a: Os grupos de canto Ava-guarani e o "ir lá" como um modo de aprendizagem durante os sonhos.

Os grupos de canto, ou corais, como são chamados no Ocoy, são muito comuns nos aldeamentos guarani e ocupam um papel importante no contexto social e cosmológico dessa população, participam ativamente das cerimônias que acontecem nas opy (casa de reza) e também se apresentam fora da aldeia, no intuito de divulgar a cultura guarani em outras cidades, estados e até mesmo em outras aldeias, onde podem também confraternizar e trocar informações com outros corais. $\mathrm{Na}$ Semana Cultural Indígena, promovida pela Escola Indígena e pela Associação Comunitária Indígena Tekoha Ocoy (ACICO) ${ }^{5}$, que acontece todos os anos durante a semana do dia índio (19 de abril), as apresentações dos corais são bastante prestigiadas e elogiadas pelos visitantes.

$\mathrm{Na}$ época da pesquisa, existiam dois corais ativos no Ocoy, sendo estes: o coral Aty Miŕ, que contava com a participação de 45 pessoas, das quais os meninos são conduzidos pelo buvixa'i (mestre) Sérgio e as meninas conduzidas pela tenondegua (mestra) Délia. O outro grupo chama-se Tupã Vy’a, do qual participavam 20 meninos conduzidos por Genuário e 10 meninas conduzidas pela jovem Rosilda.

Os cantos dos corais são chamados de mbora'i e possuem uma íntima relação com as experiências oníricas, principalmente no que diz respeito ao conteúdo dos cantos e à iniciação nos corais, geralmente, inspirados em sonhos revelatórios ou sonhos chamados.

Apesar de considerarem que atualmente há um bom número de integrantes nesses corais, os Ava-guarani exaltam um passado recente, no qual havia um número maior de participantes nos corais, formados por homens e mulheres de todas as idades que se reuniam diariamente na opy para cantar e dançar para Nhanderu. Entretanto, tem se tornado cada vez mais raro encontrarmos adultos participando desses grupos, hoje formados principalmente por crianças e adolescentes.

Vale destacar que o fato de os corais serem formados principalmente por crianças não é entendido pelos Ava-guarani como algo demeritório, pelo contrário, elas ocupam lugar de protagonistas, porque, como afirma Oliveira, as crianças que participam do coral são portadoras de saber musical e cosmológico, pois “tomam a posição de protetores, guardiões e guerreiros do grupo, categorias que possuem conotação sagrada para os Guarani” (2004, p. 63).

\footnotetext{
A Associação Comunitária Indígena Tekoha Ocoy (ACICO) foi formada em 1996 com o objetivo de discutir e deliberar, em conjunto com as lideranças, todas as questões relacionadas à aldeia, como artesanato, escola, posto de saúde, projetos desenvolvidos em pareceria com a Itaipu entre outros (Silvino Vass, vice-presidente da associação).
} 
Para o buvixa'i Sérgio Rocha, existe uma progressiva mudança na rotina de vida no Ocoy, responsável pela pouca participação dos Ava-guarani na opy e também nos corais: "As pessoas mesmo precisam trabalhar fora, mas, quando é assim, se afastam do nosso jeito de viver". Ao trabalhar fora, os Ava-guarani dispõem de menos tempo para se dedicar às atividades religiosas; em alguns casos, passam a semana toda fora, trabalhando nas plantações das cidades vizinhas e só retornam para o Ocoy no final de semana, momento em que querem descansar nas suas casas.

Existem duas opys consideradas principais no Ocoy e, por consequência, os moradores costumam optar por uma ou outra para participar com mais frequência, o que ocorre de forma bastante variável já que mudam suas escolhas de tempos em tempos. Por outro lado, os corais se dividem claramente entre uma e outra: Aty Mirí, ligada à "opy do Guilherme" ou casa de reza aberta, como é conhecida a opy mais antiga do Ocoy. Esta casa de reza está construída junto à casa do chamo'i Guilherme que reza seu mboraí três ou quatro vezes por semana, juntamente com o coral que é liderado por Délia e Sérgio, respectivamente, neta e filho deste chamo'i. O coral Tupã Vy'a, se encontra todos os dias na "opy do cacique", onde dançam e cantam a noite toda, já que as cerimônias realizadas pelo chamo’i e chara'i acontecem apenas esporadicamente.

O canto é iniciado pelo buvixa'i e acompanhado pelo som do mbaraka (chocalho), angu apu (tambor), violão e do violino tocados pelos meninos mais velhos. No centro da opy, formase uma fila de meninos e uma de meninas que se incorporam no ritmo da música, executando seus takuapu, "bastões de ritmo". Os demais presentes também se dividem, homens de um lado e mulheres de outro; nas noites mais frias, uma pequena fogueira é acesa em cada lado, e as mulheres esquentam água para o mate e assam mandi’o (mandioca) ou jety (batata doce) para todos.

Cantam e dançam por várias horas e entendem que quanto mais seus corpos ficam cansados e suados mais conectados estão com Nhanderu, porque o jeroky (dança) é capaz de tornar os corpos leves e limpos, eliminando qualquer sujeira que pode ter se acumulado no decorrer do dia em decorrência de má alimentação, quebra de jejuns ou comportamentos indevidos. No entanto, é importante abrir um parêntese para explicar que há algumas diferenças entre o mborai realizado pelos chamo'is e o mborai dos corais: enquanto o mboraí do chamo'i é um rito individualizado, os cantos entoados pelos corais são coletivos, bem como são ensinados e ensaiados por um grupo de pessoas.

Em sua obra “Terra sem mal”, Hélène Clastres (1978) já destacava essa diferenciação entre os cantos individuais, destinados principalmente aos pajés, e os cânticos que eram de caráter coletivo e nada mais eram do que preces entrecortadas por melodias, mas que ocupavam na vida dos guarani lugar privilegiado em detrimento da bela linguagem que utilizavam, capaz de não apenas aproximá-los de Nhanderu, mas de tornar homens semelhantes aos deuses.

E de onde vêm essas tão belas palavras, capazes de diminuir a distância entre homens e deuses? Normalmente, são os huvixa'is e tenondeguas que recebem em sonhos as letras e melodias desses cantos, repassados posteriormente aos participantes do coral; no entanto, qualquer participante que receber um mboraí num sonho pode transmiti-lo e ensaiá-lo aos demais. Diferente dos cantos feitos especificamente para alguma ocasião ou sobre algum tema, os cantos recebidos em sonhos não precisam ser escritos, porque ficam gravados na alma da pessoa e, por isso, jamais são esquecidos. 
As narrativas desses sonhos são bastante diferentes umas das outras, porém, geralmente, são protagonizados pela figura de Nhanderu ou de um chamo'i/chara'i que "ditam" a música inteira da forma como deverá ser executada, mas também existem relatos em que os sonhos são revelados por pássaros, parentes falecidos e anjos, podendo inclusive ser apenas uma voz distante ou um conjunto de vozes se apresentando.

A fim de exemplificar a dinâmica que envolve sonhos, canto, danças e transmissão de conhecimentos, descrevo a seguir um pequeno trecho de um sonho contado por Sérgio, buvixa'i do coral Aty Mirí:

Se tem alguém precisando de cura, se o pessoal da aldeia está fraco, com problemas, eu rezo pra Nhanderu pra pedir um mborai novo, que ajuda a dar força pros meus parentes, e dessa vez eu sonhei assim: Que uma chara'i vinha batendo o takua e me disse assim: Meu filho esse você vai levar para ensinar os outros, e depois fez um canto, um canto bem bonito que eu lembrei no outro dia para ensinar as crianças do coral. (SÉRGIO, 08/05/13).

A exemplo da experiência de Sérgio com os seus sonhos, entende-se que os sonhos podem ser considerados fontes de transmissão de conhecimento, pelos quais é possível aprender não somente as letras e melodias, mas também tudo o que se relaciona ao contexto destes corais: como e quando compartilhar os cantos, onde devem ser apresentados, os instrumentos musicais que devem ser utilizados e inclusive como executá-los.

Para algumas pessoas que, antes do "sonho chamado", não se interessavam pela opy e nem mesmo tinham conhecimento de como executar os instrumentos musicais, estes sonhos são milagrosos, porque ao acordar precisaram de pouquíssimo treino e tempo para dominar qualquer instrumento, como explica o buvixa’i Genuário ao narrar este sonho que descrevo a seguir:

Vamos dizer assim, eu estava morto mesmo, daí sonhei. Sonhei que eu fui para lá onde que o sol entrou né, e sonhei. Algum chamo’i me deu esses instrumentos (violão e violino), e todas as peças que estão aqui, tudo eles me deram aquele dia, através do sonho. Foi assim, no início eu sonhei que eu fui pra lá e achei uma escada bem comprida e bem alta, e então peguei aquela escada e fui, fui mesmo e chegou no último alto e achei outra terra que nem essa aqui e eu vi que tinha outra casa lá. Era a casa de reza, né. Fui bater na porta e abriu a porta, mas a pessoa estava rezando, só que as pessoas eram todas iguais às outras assim, seja chamo'i ou mãe, pai, aquele xondaro que estava dançando, todos iguais, o mesmo rosto, a mesma cara, não tem diferença. Falou assim pra mim: Pode entrar. E me perguntou: "por que você veio aqui? Não era para você ter vindo ainda, ninguém te chamou pra você vir ainda, o dia que for pra você vir aqui mesmo, nós mesmo vamos ir buscar você, não você vir sozinho", falou. E aí, olha pra baixo. Eu olhei pra baixo e vi meu corpo, eu estava deitado, o próprio corpo eu vi assim no chão. Você tem que ir embora de novo, mas leva esse instrumento, o dia que você estiver sofrendo, ou passar mal ou alguma coisa, para lembrar de nós, leva esse instrumento, esse instrumento é que vai salvar você. Nossa, me deu carga. Carga mesmo, me deu violino, violão, mbaraka, não sei quantos, até não me lembro porque esqueci alguma coisa, mas eu sei que eu vim pesado, carregado mesmo. E fui descendo a escada de novo, e quando pisei na terra assim, eu acordei, já era de manhã aquela hora, é por isso que eu digo: O sonho é verdade mesmo, porque eu acordei bem já. (GENUÁRIO, 02/05/2013). 
Genuário aprendeu a execução dos instrumentos no sonho ao subir os degraus do céu e se encontrar com o chamo' $i$ que lhe deu os instrumentos musicais. Estes instrumentos foram chamados de peso/carga, de modo que a força que Genuário fez para trazê-los no caminho de volta, equivale à força que precisaria fazer para aprender a tocar estes instrumentos fora de uma viagem onírica.

A respeito da exegese das letras dos mboraís, apresento, na sequência, três exemplos de cantos revelados em sonhos, permeados por uma vasta gama de assuntos e motivações. Entretanto, o objetivo de trazer essas letras para o texto não é de aprofundar um estudo interpretativo ou de significações para o conteúdo destas, mas propor um breve diálogo entre os cantos, os corais e seus mestres e a experiência onírica guarani ${ }^{6}$. As duas primeiras canções são frutos de dois sonhos de Genuário, enquanto o terceiro canto foi sonhado por Délia logo após a morte de seu irmão?

\section{Canto I sonhado por Genuário Rocha - Coral Tupã Vy’a:}

Ka'aguy Nhanderu Ogapo va’akue Mama tekoa'i

Nde rery rupi meme

Eja, eja apyma Xe-ãi.
As florestas que nosso deus Criou em teu nome Onde estão às aldeias em todas as partes do mundo. Vem conosco estamos aqui

\section{Canto II sonhado por Genuário Rocha - Coral Tupã Vy’a:}

Mboraí marae' ỹAha te jaha parve

Nhane amba'ire japorai

Nhane amba'ire japorai

Mbareterã ire jajerure

Nosso altar para cantarmos
Eu vou, vamos todos

Pedimos forças

Pedimos forças

Pedimos as forças, as bênçãos para todos

\section{Canto III sonhado por Délia - Coral Aty Mirí}

Napu'ã katu pavẽ

Napu'ã jevy pavẽ

ñanemborai jaupi

Nanderu rovai

Ñame mbarete avã

Ñame mbarete avã.
Vamos levantar todos juntos

Vamos levantar todos juntos

Nossos cantos, perante ao Deus

E perante todos os chamo'is,

Para termos a força.

Para termos a força.

De acordo com Montardo (2002), os xamãs cantam para expressar o ponto de vista dos deuses e, assim, há canto para fazer armadilha, canto para fazer anzol, canto para caçar, canto para parto, canto para afastar o mau tempo, entre outros. Acrescento que, para os Avaguarani do Ocoy, o canto é uma prece que ajuda a acalmar os corações e por esta qualidade é impreterivelmente necessário que um canto traga belas palavras que, segundo eles, dão apoio e conforto para seguirem em frente, mesmo diante das dificuldades que precisam enfrentar no cotidiano.

Sobre música e xamanismo guarani, cf. o texto e algumas indicações bibliográficas de Montardo (2002).

Os cantos foram escritos na língua guarani por Délia e Genuário e traduzidos para o português posteriormente, também por eles, com a ajuda dos demais participantes dos corais. 
Délia explicou-me que quando sentem que algo não está bem na comunidade, rezam pedindo para Nhanderu lhes mandar um mboraí em seus sonhos: Ela diz o seguinte:

Eu mesma não acreditava que meu irmão tinha morrido e eu chorava muito. Todos os dias, eu estava sempre chorando e ele veio pra mim no sonho e me mandou aquele sonho que vou escrever pra você. (DÉLIA, 17/09/2013).

O mboraí de Délia a curou da depressão que sentia pela perda do irmão e, do mesmo modo, pode ajudar outras pessoas na cura de doenças e resolução de problemas. Quando cantam sobre água, florestas, boas colheitas e sobre a abundância que viviam no passado, eles percorrem um caminho para encontrar Nhanderu e voltam a se alegrar com as possibilidades do futuro, alcançando a força que precisam para seus corpos e suas almas.

Montardo (2002) observa que, diferente do que aponta a literatura sobre um ethos pessimista que caracterizaria o povo guarani, as letras dos mboraís são um convite à alegria. Ouvi muitas pessoas falando sobre a alegria que sentem ao cantar e dançar, principalmente quando faziam um convite para ir à opy: "Você está muito triste, precisa ir na opy", "Vamos nos alegrar na opy hoje", "Hoje vou dormir bem, e amanhã o dia vai ser muito bom".

Permeados por motivos cosmológicos, estes cantos funcionam como elixir de esperança, reforçam a força do povo guarani e ainda cumprem uma função política, estimulando-os a lutar por seus direitos, na busca por melhores territórios, por políticas públicas, pela defesa da sua língua e da sua cultura. Em sua pesquisa sobre os guarani da aldeia M’Biguaçu em Santa Catarina, Oliveira (2013) destaca que os corais são também uma fonte de renda alternativa para aldeia, e cumprem um papel de interação entre os guarani e os djuruá (não indígenas), em que o canto e a dança são eleitos como símbolo diacrítico. Segundo a autora, os corais revelam um investimento consciente e sistemático no ensino-aprendizagem dos cantos, danças, toque de instrumentos e até mesmo da concentração (2013, p.107).

As crianças menores aprendem com as crianças maiores e com os mestres a executar os instrumentos, confeccionar os pequenos petynguas (cachimbo sagrado) que utilizam na opy, aprendem os passos, os cantos e, principalmente, tomam lições diárias de como viver o nhandereko (jeito de ser guarani). $\mathrm{Na}$ "opy do cacique" - construída principalmente para o ensaio do coral Tupã Vy'a e onde fazem apresentações para os visitantes - acontecem pequenas palestras durante os ensaios, chamadas de "conselhos", nas quais os mestres falam para as crianças de o quanto é importante frequentar a opy diariamente, ter disciplina para aprender com os mais velhos e se concentrar, respeitando o que estão cantando e dançando.

Por tudo isso, torna-se importante ressaltar que os sonhos e suas interpretações são ferramentas fundamentais na manutenção do nhandereko, ou seja, do jeito de ser guarani. Sonhar, compartilhar e interpretar as imagens das viagens oníricas são processos acessíveis a qualquer Ava-guarani, são a base do conhecimento dos especialistas, como os xamãs e os mestres dos corais, mas também podem ser acessados pelas crianças e demais pessoas que não se consideram possuidoras das especialidades xamânicas. 


\section{Referências}

BARTOLOMÉ, Miguel; BARABAS, Alicia. Os sonhos e os dias. Xamanismo no México Atual. Revista Mana, Rio de Janeiro, v. 19, n, 1, p.7-37, fev., 2013.

CLASTRES, Hélène. Terra sem mal: o profetismo tupi guarani. Brasiliense: São Paulo, 1978.

LANGDON, Esther Jean. Representações do poder xamanístico nas narrativas dos sonhos Siona. Revista Ilha. Florianópolis, n.0, p.35-56, out.1999.

MONTARDO, Deise L. Oliveira. Através do Mbaraka: música e xamanismo guarani. São Paulo, Tese (doutorado em antropologia) - Programa de pós-graduação em antropologia social - USP, 2002.

OLIVEIRA, S. Melissa. Infância, educação e religião entre os Guarani de M"Biguaçu, SC. Florianópolis. Dissertação de mestrado - Programa de pós-graduação em antropologia social UFSC, 2004.

OTERO, Júlia S. Vagares da alma: elaborações ameríndias acerca do Sonhar. Dissertação de mestrado apresentada ao programa de Antropologia Social da Universidade de Brasília, UNB, 2010.

TASSINARI, Antonella M. A educação escolar indígena no contexto da Antropologia brasileira. Revista Ilha. Florianópolis, v.10, n.1, p.218-244, 2008. 